\title{
Proxy variables and nonparametric identification of causal effects
}

\author{
Xavier de Luna \\ Philip Fowler \\ Per Johansson
}


The Institute for Evaluation of Labour Market and Education Policy (IFAU) is a research institute under the Swedish Ministry of Employment, situated in Uppsala. IFAU's objective is to promote, support and carry out scientific evaluations. The assignment includes: the effects of labour market and educational policies, studies of the functioning of the labour market and the labour market effects of social insurance policies. IFAU shall also disseminate its results so that they become accessible to different interested parties in Sweden and abroad.

IFAU also provides funding for research projects within its areas of interest. The deadline for applications is October 1 each year. Since the researchers at IFAU are mainly economists, researchers from other disciplines are encouraged to apply for funding.

IFAU is run by a Director-General. The institute has a scientific council, consisting of a chairman, the Director-General and five other members. Among other things, the scientific council proposes a decision for the allocation of research grants. A reference group including representatives for employer organizations and trade unions, as well as the ministries and authorities concerned is also connected to the institute.

Postal address: P.O. Box 513, 75120 Uppsala

Visiting address: Kyrkogårdsgatan 6, Uppsala

Phone: +4618 4717070

Fax: +4618471 7071

ifau@ifau.uu.se

www.ifau.se

Papers published in the Working Paper Series should, according to the IFAU policy, have been discussed at seminars held at IFAU and at least one other academic forum, and have been read by one external and one internal referee. They need not, however, have undergone the standard scrutiny for publication in a scientific journal. The purpose of the Working Paper Series is to provide a factual basis for public policy and the public policy discussion.

ISSN 1651-1166 


\title{
Proxy variables and nonparametric identification of causal effects ${ }^{\mathrm{a}}$
}

\author{
by \\ Xavier de Luna ${ }^{\mathrm{b}}$, Philip Fowler ${ }^{\mathrm{c}}$ and Per Johansson ${ }^{\mathrm{d}}$
}

June 30, 2016

\begin{abstract}
Proxy variables are often used in linear regression models with the aim of removing potential confounding bias. In this paper we formalise proxy variables within the potential outcome framework, giving conditions under which it can be shown that causal effects are nonparametrically identified. We characterise two types of proxy variables and give concrete examples where the proxy conditions introduced may hold by design.
\end{abstract}

Keywords: average treatment effect, observational studies, potential outcomes, unobserved confounders

JEL-codes: C14

\footnotetext{
${ }^{\mathrm{a}} \mathrm{We}$ are grateful to Ingeborg Waernbaum and Inga Laukaityte for helpful comments that have improved the paper. Financial support from the Swedish Council for Working Life and Social Research (DNR 20090826) is gratefully acknowledged.

${ }^{b}$ Department of Statistics, USBE, Umeå University, Umeå, Sweden

${ }^{c}$ Corresponding Author. Email: philip.fowler@umu.se; Department of Statistics, USBE, Umeå University, Umeå, Sweden

${ }^{\mathrm{d}}$ Department of Statistics, Uppsala University, Uppsala, Sweden; Institute for Evaluation of Labour Market and Education Policy, Uppsala, Sweden; The Institute for the Study of Labor IZA, Bonn, Germany
} 


\section{Table of contents}

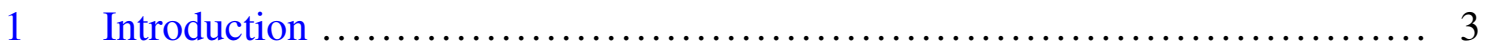

2 Theory on proxy variables ..................................... 3

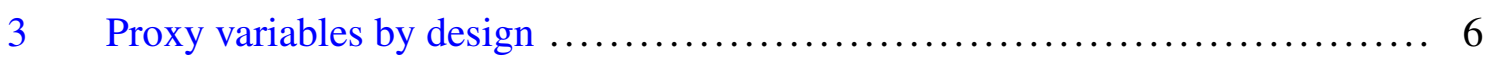

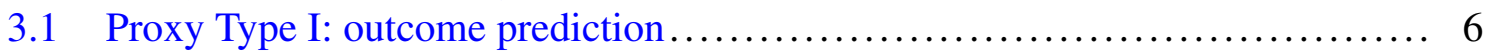

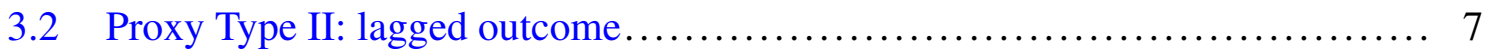

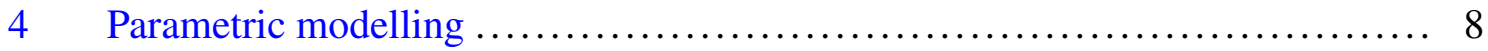

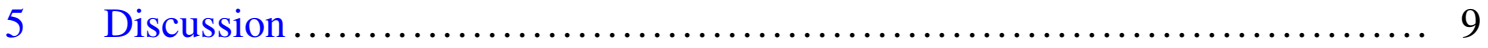

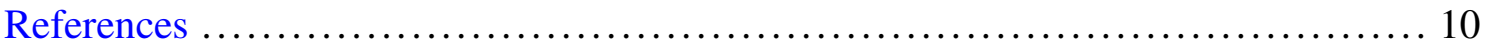




\section{Introduction}

Proxy variables are often used in empirical economics and other empirical sciences as substitutes for unobserved confounders when conducting observational studies. However, using substitute variables does not necessarily reduce bias due to confounding to zero and may even increase bias (Frost 1979). Thus, we call herein proxy variables only such substitute variables which yield identification of a causal effect of interest. Proxy variables have previously been defined in the literature in the context of linear models, using for instance linear projection orthogonality conditions; see Wooldridge (2010, pp. 67-72).

In this note we formalise proxy variables within the potential outcome framework (Imbens and Wooldridge 2009), giving conditions for which it can be shown that causal effects are nonparametrically identified. This allows us to clarify the use of proxy variables in a general context. Moreover, our approach also allows us to characterise two types of proxy variables, one directly related to the earlier definition mentioned above, and a new type of proxy variable not previously considered in the literature. We also give examples where the proxy conditions introduced may hold by design.

\section{Theory on proxy variables}

We consider a study with the aim to evaluate the effect of a binary treatment $T$ on an outcome $Y$. Let $Y_{1}$ and $Y_{0}$ be potential outcomes if treated $(T=1)$ and not treated $(T=0)$, respectively, $\boldsymbol{X}$ a set of observed pre-treatment covariates related to $T$ and $Y$ (observed confounders), and $\boldsymbol{U}$ a set of unobserved pre-treatment covariates also related to $T$ and $Y$ (unobserved confounders). We assume that the observed outcome for any given unit is $Y=T Y_{1}+(1-T) Y_{0}$, i.e. that the consistency and the stable unit treatment value assumption hold (see Rubin 1980). Letting $A \Perp B \mid C$ denote that $A$ is conditionally independent of $B$ given $C$ (Dawid 1979), the following assumptions are used in the sequel.

Assumption 1 (Unconfoundedness).

i) $\quad T \Perp Y_{0} \mid(\boldsymbol{X}, \boldsymbol{U})$,

ii) $T \Perp Y_{1} \mid(\boldsymbol{X}, \boldsymbol{U})$. 
Assumption 2 (Common support).

$$
\begin{aligned}
& \text { i) } \quad \operatorname{Pr}(T=0 \mid \boldsymbol{X}, \boldsymbol{U})>0, \\
& \text { ii) } \quad \operatorname{Pr}(T=1 \mid \boldsymbol{X}, \boldsymbol{U})>0 .
\end{aligned}
$$

If in Assumptions 1 and 2 the set of unobserved covariates $\boldsymbol{U}$ is empty, then the average causal effect $\tau=E\left(Y_{1}-Y_{0}\right)$ and the average causal effect on the treated $\tau^{t}=E\left(Y_{1}-Y_{0} \mid\right.$ $T=1)$ are identified. While if $\boldsymbol{U}$ is empty only for Assumptions $1 i$ and $2 i$ then only $\tau^{t}$ is identified (Imbens and Wooldridge 2009).

In observational studies, it may be the case that, although $\boldsymbol{U}$ is not observed, we have observed variables which may act as proxies for $\boldsymbol{U}$. We now give conditions characterising proxy variables useful for identification of average causal effects. Let $\boldsymbol{P}$ denote a nonempty set of pre-treatment variables not included in the covariate sets defined so far, $\boldsymbol{P} \nsubseteq\{\boldsymbol{X}, \boldsymbol{U}\}$, and let $\boldsymbol{U}$ be non-empty such that $Y_{0} \not \Perp t \mid \boldsymbol{X}$ and/or $Y_{1} \not \Perp t T \mid \boldsymbol{X}$. A proxy variable will then need to satisfy $Y_{0} \Perp T \mid(\boldsymbol{X}, \boldsymbol{P})$ (and $Y_{1} \Perp T \mid(\boldsymbol{X}, \boldsymbol{P})$ ) in order for $\tau^{t}$ $(\tau)$ to be identified. A set of conditions describing useful proxy properties for $\boldsymbol{P}$ are as follows.

Assumption 3 (Proxy Type I).

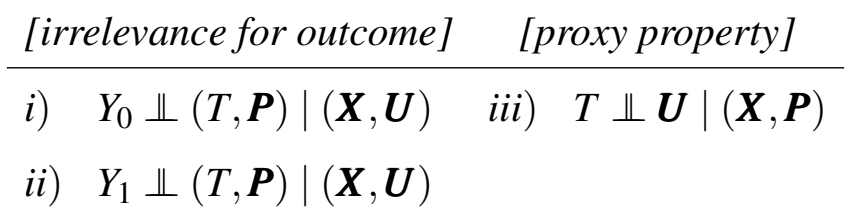

This first type of proxy is similar in spirit to Wooldridge's (2010) definition of proxy variables. A proxy variable of Type I is an irrelevant variable for explaining the potential outcomes given the confounders $\boldsymbol{X}, \boldsymbol{U}$ (Assumptions $3 i-i i$ ). A variable irrelevant for the outcome is useful for identification (see Proposition 1 below) when it makes $\boldsymbol{U}$ irrelevant for the treatment (Assumption 3iii).

We consider further another type of useful proxy variable, which to our knowledge has not been formalised in the literature. 
Assumption 4 (Proxy Type II).

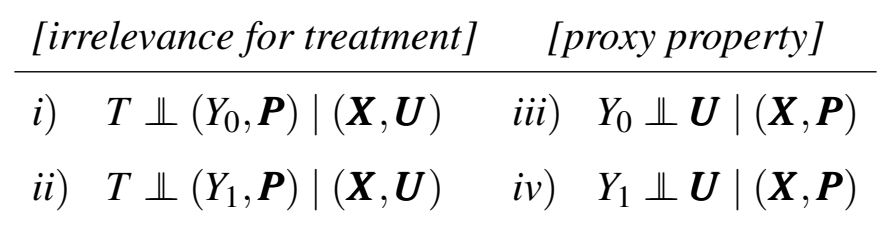

Thus, a proxy variable of Type II is such that it is irrelevant for explaining the treatment assignment given the confounders $(\boldsymbol{X}, \boldsymbol{U})$ (Assumptions $4 i-i i)$. A variable irrelevant for the treatment is useful for identification (see Proposition 2 below) when it makes $\boldsymbol{U}$ irrelevant for the outcome (Assumptions 4iii-iv).

We will also need an extension of the common support assumption for identification purposes.

Assumption 5 (support on proxy).

$$
\begin{aligned}
& \text { i) } \operatorname{Pr}(T=0 \mid \boldsymbol{X}, \boldsymbol{P})>0, \\
& \text { ii) } \operatorname{Pr}(T=1 \mid \boldsymbol{X}, \boldsymbol{P})>0 \text {. }
\end{aligned}
$$

Lemma 1 (Dawid (1979)). For any variables $A, B, C$ and $D$, it follows that:

$A \Perp B \mid C$ and $A \Perp D|(B, C) \Longleftrightarrow A \Perp(D, B)| C$.

Proposition 1. If Assumptions 3i, 3iii, and 5i hold, then $\tau^{t}$ is identified. Moreover, if also Assumptions 3ii and 5ii hold, then both $\tau$ and $\tau^{t}$ are identified.

Proof. By Lemma 1 we have that

$$
T \Perp \boldsymbol{U} \mid(\boldsymbol{X}, \boldsymbol{P}) \text { and } T \Perp Y_{0}\left|(\boldsymbol{U}, \boldsymbol{X}, \boldsymbol{P}) \Longleftrightarrow T \Perp\left(Y_{0}, \boldsymbol{U}\right)\right|(\boldsymbol{X}, \boldsymbol{P}) \text {. }
$$

The first part of the left-hand side of (1) holds by Assumption 3iii. The second part of the left-hand side of (1) holds by Assumption 3i, using Lemma 1 to note that $Y_{0} \Perp$ $(T, \boldsymbol{P})\left|(\boldsymbol{X}, \boldsymbol{U}) \Rightarrow Y_{0} \Perp T\right|(\boldsymbol{U}, \boldsymbol{X}, \boldsymbol{P})$. Since the left-hand side of (1) holds, it follows that $T \Perp\left(Y_{0}, \boldsymbol{U}\right) \mid(\boldsymbol{X}, \boldsymbol{P})$, which by Lemma 1 implies that $T \Perp Y_{0} \mid(\boldsymbol{X}, \boldsymbol{P})$. Thus, that Assumption $5 i$ holds yields identification of $\tau^{t}$. Similarly, if Assumption 3ii holds, then $T \Perp Y_{1} \mid(\boldsymbol{X}, \boldsymbol{P})$. Finally, if Assumptions 3 and 5 hold, then $\tau$ is identified. 
Proposition 2. If Assumptions 4i, 4iii, and 5i hold, then $\tau^{t}$ is identified. Moreover, if also Assumptions 4ii, 4iv, and 5ii hold, then both $\tau$ and $\tau^{t}$ are identified.

Proof. The proof is similar to the proof of Proposition 1 and thus omitted.

\section{Proxy variables by design}

Proxy variables may be obtained by design and here we give some examples. For the sake of simplicity, we focus on univariate proxy variables $P$ in the sequel.

\subsection{Proxy Type I: outcome prediction}

We characterise here a natural situation where a proxy of Type I arises. Let

$$
Y_{0}=h(\boldsymbol{X}, \boldsymbol{U})+\varepsilon_{Y},
$$

where $\varepsilon_{Y}$ is exogenous and $h(\boldsymbol{X}, \boldsymbol{U})=E\left(Y_{0} \mid \boldsymbol{X}, \boldsymbol{U}\right)$. Assume that a prediction $P$ of $Y_{0}$, made before the treatment assignment, is available such that

$$
P=h(\boldsymbol{X}, \boldsymbol{U})+\varepsilon_{P},
$$

where $\varepsilon_{P} \Perp\left(\boldsymbol{X}, \boldsymbol{U}, Y_{0}\right)$ and $E\left(\varepsilon_{P}\right)=0$, i.e. the prediction is unbiased. Consider further a study design where the treatment assignment is a function of $P$ and $\boldsymbol{X}$ as follows:

$$
T^{*}=k(P, \boldsymbol{X})+\varepsilon_{T},
$$

for some function $k(\cdot)$, with $\varepsilon_{T}$ exogenous and where $\operatorname{Var}\left(\varepsilon_{T}\right)>0$. Let the treatment assignment be such that $T=1$ if $T^{*}>0$ and $T=0$ otherwise. By exogeneity of $\varepsilon_{Y}$, we have that $Y_{0} \Perp(T, P) \mid(\boldsymbol{X}, \boldsymbol{U})$, i.e. Assumption $3 i$ holds. Also, $T \Perp \boldsymbol{U} \mid(\boldsymbol{X}, P)$ by design, i.e., Assumption 3iii is fulfilled. Suppose further that $k(\cdot)$ and $\varepsilon_{T}$ are chosen in such a way that Assumption $5 i$ is fulfilled. Note that the design error $\varepsilon_{T}$ is necessary in order for $\operatorname{Pr}(T=0 \mid \boldsymbol{X}, P)>0$. Then $\tau^{t}$ is identified by Proposition 1 .

Example 1 (Outcome prediction proxy by design). Consider the situation where a treatment $T$ is a social program for the unemployed, whose effect on duration to employ- 
ment, $Y$, we want to evaluate. Suppose treatment is assigned by case workers after interviews with eligible individuals. A set of individual and labor market characteristics $\boldsymbol{X}$ are recorded at the time of the interview. At that time, the case worker also makes a prediction $P$ of the unemployment duration, would the individual not be assigned to treatment (i.e., a prediction of $Y_{0}$ ). Then, arguably the case workers will provide an unbiased prediction of $Y_{0}$, based on $\boldsymbol{X}$ and other unobserved information $\boldsymbol{U}$ obtained at interview, i.e. such that (2-3) hold. Furthermore, if we believe that $P$ summarises all information in $\boldsymbol{U}$ necessary to make the treatment assignment decision, such that (4) holds, then $P$ is a proxy of Type I. In practice, the latter statement may be difficult to ensure by design and an analysis of the sensitivity to Assumption 3iii may be useful.

\subsection{Proxy Type II: lagged outcome}

A Type II proxy variable may be available in a follow up setting with three time periods, $t=0,1,2$. Assume that the outcome $Y$ is observed at time $t=2$. Further, let $\boldsymbol{X}$ and $\boldsymbol{U}$ be defined at baseline $(t=0)$, with $\boldsymbol{X}$ potentially including the outcome measured at $t=0$. We also observe the outcome at $t=1$, denoted $Y^{l}$, simultaneously as treatment $T$ is assigned. Then, with such a design it may be realistic to assume that

$$
\begin{aligned}
& Y^{l}=l(\boldsymbol{X}, \boldsymbol{U})+\varepsilon_{L}, \quad T^{*}=m(\boldsymbol{X}, \boldsymbol{U})+\varepsilon_{T}, \\
& T=1 \text { if } T^{*}>0 \text { and } T=0 \text { otherwise, }
\end{aligned}
$$

for some functions $l(\cdot)$ and $m(\cdot)$ and where $\varepsilon_{L}$ and $\varepsilon_{T}$ are exogenous error terms. Furthermore, if we have

$$
Y_{0}=q\left(\boldsymbol{X}, Y^{l}\right)+\varepsilon_{Y}
$$

for some function $q(\cdot)$ and where the error term $\varepsilon_{Y}$ is exogenous, then $T \Perp\left(Y^{l}, Y_{0}\right) \mid$ $(\boldsymbol{X}, \boldsymbol{U})$. Thus, by design $P=Y^{l}$ fulfills Assumption $4 i$, i.e. $Y_{l}$ is irrelevant for the treatment assignment $T$. Moreover, $Y_{0} \Perp \boldsymbol{U} \mid\left(\boldsymbol{X}, Y^{l}\right)$, i.e. Assumption 4iii also holds. The validity of (5) should be investigated through a sensitivity analysis. Finally, to guarantee that $5 i$ holds here, a sufficient condition is that Assumption 2 holds together with $\operatorname{Pr}\left(\boldsymbol{U} \mid \boldsymbol{X}, Y^{l}\right)>0$. 
Example 2 (Lagged outcome proxy design). An example of a lagged outcome proxy design is given in Wooldridge (2010, Ex. 4.4), where data on Michigan manufacturing firms are discussed with the purpose to estimate the effect of job training grants $(T)$ on firms' productivity. A factor giving a measure of the latter is log scrap rate (number of items out of 100 that must be scrapped), here denoted by $Y$. Wooldridge used years 1988 and 1987 for the purpose of illustration, that is where $T$ and outcome $Y$ are measured in 1988, and argued that $Y_{87}(\log$ scrap rate in 1987) is a proxy of Type I, i.e. in our framework such that $T \Perp U \mid Y_{87}$, where $U$ represents unobserved productivity factors. However, one may arguably think that it is more realistic to view $Y_{87}$ as a proxy of Type II, i.e. such that $Y \Perp U \mid Y_{87}$.

\section{Parametric modelling}

We now turn our attention to a linear model where a variable $P$ is a proxy variable of Type I. Suppose that we have potential outcomes such that:

$$
\begin{aligned}
& Y_{0}=\alpha_{0}+\boldsymbol{\beta}_{0}^{\prime} \boldsymbol{X}+\gamma U+\varepsilon_{0}, \\
& Y_{1}=\alpha_{1}+\boldsymbol{\beta}_{1}^{\prime} \boldsymbol{X}+\gamma U+\varepsilon_{1},
\end{aligned}
$$

where $\varepsilon_{j}, j=0,1$, are exogenous variables with mean zero and independent of each other. Let $P$ be such that (3) holds. Then $Y_{j} \Perp(P, T) \mid(\boldsymbol{X}, U), j=0,1$, and Assumptions $3 i-i i$ are fulfilled.

By Lemma 1 it follows from Assumption 3 that $Y_{j} \Perp P \mid(X, U, T), j=0,1$. By consistency it follows that $Y \Perp P \mid(\boldsymbol{X}, U, T)$. This implies that $E(Y \mid T, \boldsymbol{X}, U, P)=E(Y \mid$ $T, \boldsymbol{X}, U)$, which is in analogy with the redundancy condition in Wooldridge (2010, p. 68). Furthermore, let

$$
U=E(U \mid \boldsymbol{X}, P)+r
$$

where $E(U \mid \boldsymbol{X}, P)=\theta_{0}+\boldsymbol{\theta}^{\prime} \boldsymbol{X}+\phi P$ and assume that $r \Perp T \mid(\boldsymbol{X}, P)$. Then, $U \Perp T \mid(\boldsymbol{X}, P)$, i.e. $P$ fulfills Assumption 3iii. Given (8) it also follows that $L(U \mid 1, \boldsymbol{X}, P, T)=L(U \mid$ $1, X, P)$, where $L(A \mid B)$ is the linear projection of $A$ on $B$. This corresponds to condition 
(4.26) in Wooldridge (2010, p. 68). In summary, in this situation $P$ is a proxy of Type I and a proxy as defined by Wooldridge (2010). If Assumption 5 holds, then, by Proposition $1, \tau$ is identified. Note however that if $\gamma$ in (6) and (7) instead is $\gamma_{0}$ and $\gamma_{1}$ respectively, then identification is not achieved through a linear model.

\section{Discussion}

Proxies are often used in empirical economics in order to block unobserved confounding in observational studies. In this paper we have given formal conditions under which proxies yield nonparametric identification of average causal effects.

In many applications, an unobserved characteristic is replaced by an observed variable believed to be a function of the former, in the spirit of (3). For example, in Wooldridge (2010, Ex. 4.3), ability is replaced by IQ. The key issue is whether such a variable is a proxy as defined in this article, and in particular whether Assumption 3iii holds or not. In the ability-IQ situation, it seems reasonable to believe that $I Q=f c t$ (Ability) $+\varepsilon_{I Q}$. However, assuming that $T^{*}=f c t(I Q)+\varepsilon_{T}$ (in the sense of (4)) is not realistic since one would instead expect $T^{*}=f c t$ (Ability) $+\varepsilon_{T}$ to hold. Thus, IQ is not a proxy as defined herein, but rather a measure of ability with error. Conditioning on the latter may yield bias; see Pearl (2010). 


\section{References}

Dawid, A. P. (1979). Conditional independence in statistical theory. Journal of the Royal Statistical Society. Series B (Methodological), 41(1):1-31.

Frost, P. A. (1979). Proxy variables and specification bias. The Review of Economics and Statistics, 61(2):323-325.

Imbens, G. W. and Wooldridge, J. M. (2009). Recent developments in the econometrics of program evaluation. Journal of Economic Literature, 47(1):5-86.

Pearl, J. (2010). On measurement bias in causal inference. In Proceedings of the TwentySixth Conference on Uncertainty in Artificial Intelligence, pages 425-432. AUAI Press.

Rubin, D. B. (1980). Randomization analysis of experimental data: The Fisher randomization test comment. Journal of the American Statistical Association, 75(371):591593.

Wooldridge, J. M. (2010). Econometric Analysis of Cross Section and Panel Data. The MIT Press, Cambridge, Massachusetts, 2nd edition. 


\section{Publication series published by IFAU - latest issues}

\section{Rapporter/Reports}

2016:1 Engdahl Mattias and Anders Forslund "En förlorad generation? Om ungas etablering på arbetsmarknaden"

2016:2 Bastani Spencer, Ylva Moberg and Håkan Selin ”Hur känslig är gifta kvinnors sysselsättning för förändringar i skatte- och bidragssystemet?”

2016:3 Lundin Martin, Oskar Nordström Skans and Pär Zetterberg ”Kåren och karriären: Studentpolitiken som språngbräda”

2016:4 Brommesson Douglas, Gissur Erlingsson, Johan Karlsson Schaffer, Jörgen Ödalen and Mattias Fogelgren "Att möta den högre utbildningens utmaningar"

2016:5 Egebark Johan ”Effekter av skatter på ungas egenföretagande”

2016:6 Mannelqivst Ruth, Berndt Karlsson and Bengt Järvholm ”Arbete och arbetsmarknad i sjukförsäkringen”

2016:7 Rosenqvist Olof "Rösträtt och ungdomars kunskap om politik"

2016:8 Lindgren Karl-Oskar, Sven Oskarsson and Mikael Persson ”Leder bättre tillgång till utbildning till ökat politiskt deltagande?”

2016:9 Moberg Ylva "Är lesbiska föräldrar mer jämställda?”

2016:10 Hinnerich Björn T. and Jonas Vlachos "Skillnader i resultat mellan gymnasieelever i fristående och kommunala skolor"

2016:11 Engdahl Mattias "Invandringens arbetsmarknadseffekter: lärdomar från den internationella litteraturen och svenska resultat"

2016:12 Hagen Johannes ”Hälsoeffekter av senarelagd pensionering”

\section{Working papers}

2016:1 Bastani Spencer, Ylva Moberg and Håkan Selin "Estimating participation responses using transfer program reform"

2016:2 Lundin Martin, Oskar Nordström Skans and Pär Zetterberg "Leadership experiences, labor market entry and early career trajectories"

2016:3 van den Berg Gerard J., Lena Janys, Enno Mammen and Jens P. Nielsen "A general semiparametric approach to inference with marker-dependent hazard rate models"

2016:4 Egebark Johan "Effects of taxes on youth self-employment and income"

2016:5 Holmlund Helena "Education and equality of opportunity: what have we learned from educational reforms?"

2016:6 Rosenqvist Olof "Rising to the occasion? Youth political knowledge and the voting age"

2016:7 Lindgren Karl-Oskar, Sven Oskarsson and Mikael Persson "How does access to education influence political candidacy? Lessons from school openings in Sweden"

2016:8 Moberg Ylva "Does the gender composition in couples matter for the division of labor after childbirth?”

2016:9 Hinnerich Björn T. and Jonas Vlachos "The impact of upper-secondary voucher school attendance on student achievement. Swedish evidence using external and internal evaluations"

2016:10 Farbmacher Helmut, Raphael Guber and Johan Vikström "Increasing the credibility of the twin birth instrument"

2016:11 Hagen Johannes "What are the health effects of postponing retirement? An instrumental variable approach"

2016:12 de Luna Xavier, Philip Fowler and Per Johansson "Proxy variables and nonparametric identification of causal effects" 


\section{Dissertation series}

2016:1 Hagen Johannes "Essays on pensions, retirement and tax evasion” 